\title{
O modelo institucional dos anos 30 e a presente crise brasileira
}

BOLfVAR LAMOUNIER

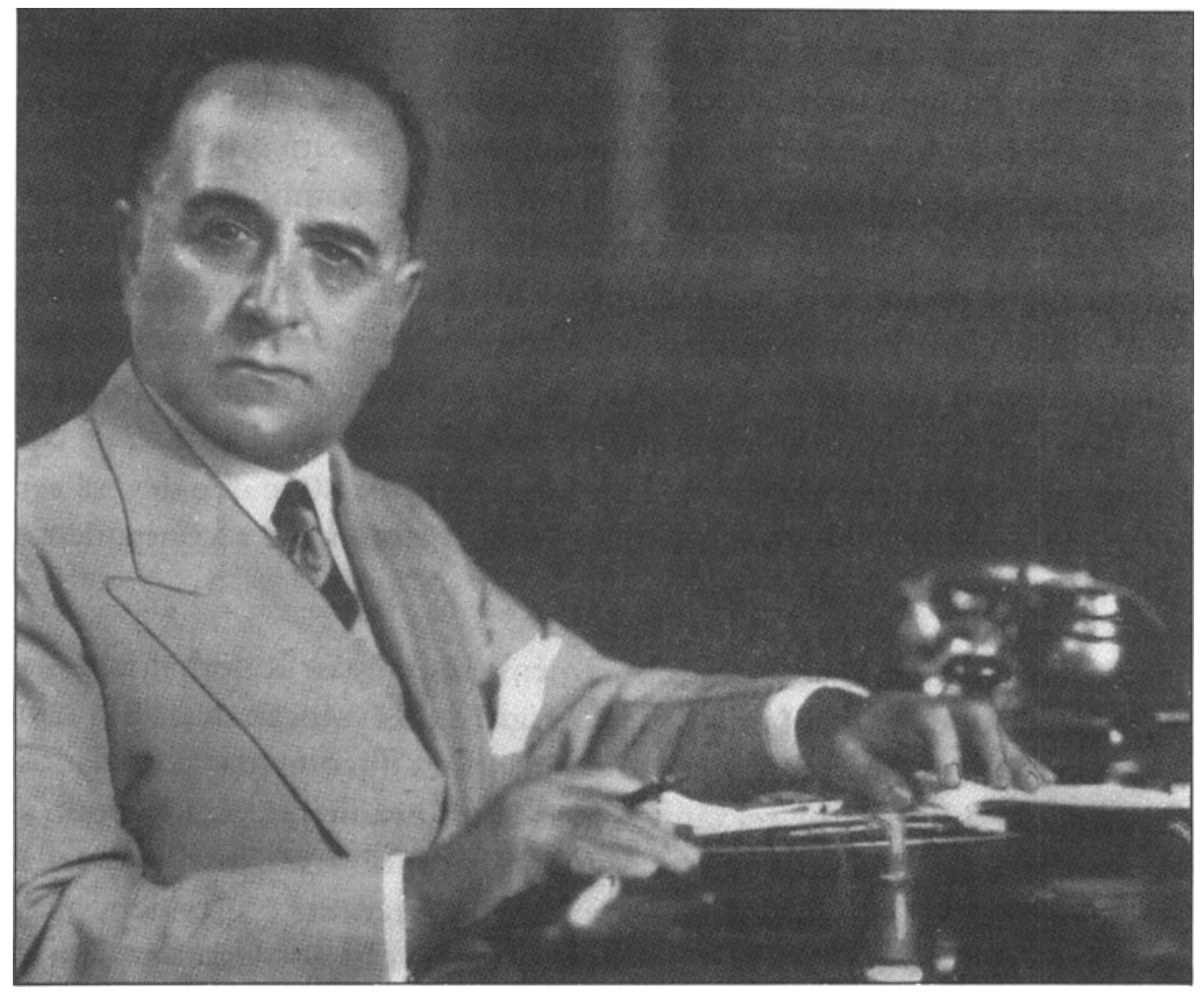

e as mudanças econômicas implementadas no Brasil a partir de 1930 estão bem estudadas, o mesmo não se pode dizer da estrutura político-institucional erigida a partir da Revolução de 1930. No ângulo predominantemente economicista em que se situam, as análises sociopolíticas disponíveis mal fazem referência a balizamentos institucionais, prendendo-se, na maioria dos casos, aos grandes agregados sociais da teoria marxista. Esboçar uma interpretação mais consistente dessa evolução político-institucional e de suas conexões com a presente 
crise brasileira é o objetivo central deste ensaio. O pressuposto geral é que estamos vivendo o final de um ciclo. Sob o ponto de vista econômico, seu esgotamento pode ser visto como um efeito vebleniano, ou seja, a exaustão em consequiência do próprio sucesso alcançado numa fase anterior. De fato, o modelo de industrialização induzida pelo Estado assegurou ao Brasil, durante várias décadas, taxas de crescimento extremamente elevadas, transformando o País num show-case de industrialização acelerada. O esgotamento se deve, entre outras razões, à consolidação de vantagens adquiridas, sob a forma de rent-seeking e ao rotundo fracasso daquele modelo sob o prisma social-redistributivo. Hoje o Brasil é também um show-case no que se refere à pobreza, à péssima distribuiçâo da renda e à intensidade das tensóes sociais (1).

$\mathrm{Na}$ área político-institucional, a questão é mais complexa. Nossa tese é que o modelo institucional que começa a ser estabelecido nos anos 30 assenta-se sobre um tripé extremamente problemático no que se refere à conformação individual de cada um dos três componentes, e mais ainda quando se pensa na combinação dos três numa mesma estrutura institucional: arranjos exacerbadamente consociativos na esfera eleitoral-partidária, corporativismo na área sindical, e presidencialismo plebiscitário como suposto fator de unificação, na cumieira do sistema político (2). Corrigir ou substituir inteiramente este mecanismo institucional é o debate que se vem travando desde meados dos anos 80 , e que deverá ser concluído em 1993/94, com a realização do plebiscito e a conseqüente revisão do texto constitucional.

Meu argumento será desdobrado em três etapas. Referir-me-ei na primeira ao modelo econômico que emergiu da Revolução de 1930, não para fazer uma reconstrução detalhada, mas para documentar com dados de pesquisa o importante reexame que as elites brasileiras vêm fazendo a esse respeito (3). Deixarei para a segunda parte o tripé institucional a que acima me referi: consociativismo, corporativismo e presidencialismo. Direi alguma coisa sobre as origens e a evoluçáo desse modelo e apontarei algumas de suas debilidades nas atuais condiçóes do País. $\mathrm{Na}$ terceira, farei uma avaliaçáo sintética das propostas de reforma institucional ora em debate - especialmente a implantação de um regime parlamentarista e a mudança do sistema eleitoral. Antecipando e resumindo o argumento central, direi que se acha em curso uma acelerada reorientação ideológica, com uma crescente conviç̧áo de que o modelo dos anos 30 está esgotado, econômica e institucionalmente. Essa reorientaçáo está em parte ligada a fatores internos: à estagflaçăo dos anos 80, ainda não superada; ao temor à ingovernabilidade; à consciência da grave deterioração social que vem ocorrendo num país já dilacerado por 
desigualdades profundas. Mas em parte ela se deve ao portentoso impacto das mudanças ocorridas no Leste Europeu, que redesenharam o mapa-múndi ideológico deste limiar dos anos 90.

\section{Estado e industrialização: a penosa revisão de um modelo}

É certo que um movimento revolucionário vinha sendo articulado por dissidências da elite em alguns dos principais estados antes mesmo da crise de 1929. Numa reflexão mais ampla, pode-se também dizer que as principais direçóes da política pública que emergiram entre 1930 e 1945, como a institucionalização da intervenção regulatória do Estado na economia, e especialmente nas relações capital/trabalho, a constituição de um setor público empresarial, a centralização do poder, corrigindo os excessos federativos da Constituição de 1891, e até mesmo a progressiva afirmação de uma ideologia de nacionalismo econômico, vinham sendo lentamente gestadas no bojo da Primeira República. Esses embriốes de mudança tinham origens e motivaçóes diversas, mas convergiam numa aguda preocupação com a debilidade do Estado e da economia agroexportadora sobre a qual se assentava. Essas debilidades vinham sendo debatidas desde a antevéspera da Primeira Guerra Mundial por intelectuais, políticos, empresários e militares - sendo concebível que levassem, mais cedo ou mais tarde, a alteraçóes institucionais importantes. Estes antecedentes não devem porém levar-nos a subestimar o impacto da crise de 1929, que sem dúvida acentuou as convergências latentes e deu feição imediatamente prática àqueles anseios e preocupaçóes.

Associando-se ao movimento revolucionário então em curso, como agente precipitador, a crise de 1929 reforçou a tendência à mudança, contribuindo para a eclosão de importantes deslocamentos de poder na sociedade brasileira. Considerado em sua composição social e em seu discurso pré-Revolução, o movimento chefiado por Getúlio Vargas não transcendia significativamente o horizonte dos conflitos intra-elite que lavravam desde o início do regime republicano. $\mathrm{Na}$ origem, a Revoluçáo mal se distinguia das contendas que ocorriam continuamente entre as fraçóes regionais da exígua oligarquia que entáo controlava o País. Apesar desse caráter limitado da coalizáo inicial, amplamente reconhecido, mudanças importantes seguiram-se à derrubada do governo de Washington Luís (1926-1930). A Revolução alterou substancialmente o modus operandi do sistema político, reestruturando os canais de acesso ao poder federal e dando início a uma série de mudanças substanciais, tanto práticas quanto ideológicas. Justamente neste sentido é que se pode entender a Revolução de 1930 como o momento focal do processo 
brasileiro de state-building: uma forte inflexão centralizadora no aparelho estatal, corrigindo o regionalismo excessivo da Velha República, e, ao mesmo tempo, uma inflexão na política econômica, que se orienta cada vez mais no sentido do nacionalismo e da industrialização. Inicialmente reflexa, poder-se-ia mesmo dizer instintiva, essa política foi aos poucos assumida como visăo doutrinária, ou seja, como um modelo de industrialização, cujo motor viria a ser uma forte presença empresarial do Estado nos setores de infra-estrutura.

Decorridas seis décadas, o País dispóe hoje de uma base industrial significativa. Ao contrário da Argentina, onde o avanço industrial foi dificultado pelos conflitos políticos do período pós-1930 e continuou bloqueado durante as intervençóes militares, o Brasil sustentou elevadas taxas de crescimento até o início dos anos 80 . Esse sucesso na promoção do crescimento e o papel crucial que nele desempenharam grandes empresas estatais conferiram ao antigo modelo getulista-desenvolvimentista uma legitimidade inegável. À medida, porém, que se configurava a estagflação dos anos 80 (a chamada "década perdida" ), o sucesso anterior desse modelo passou a dificultar a aceitação de um modelo distinto, baseado num controle mais rigoroso do déficit público, na redução da intervenção empresarial e regulatória do Estado na economia, e na busca de políticas públicas eficazes na área social. Neste sentido, o fermento ideológico de hoje está centrado na crescente convicçẩo de que tais reformas são de fato necessárias, que não refletem apenas a obsessão neoliberal de uma minoria conservadora, e que precisam ser efetivadas por mais que a opinião pública e o Congresso rejeitem um governo - o do presidente Fernando Collor - que delas fez o cerne de seu discurso.

De fato, o governo Collor inicia o ano de 1992 extremamente desgastado. Às vésperas de completar o seu segundo ano de mandato, em março, todas as pesquisas de popularidade $\mathrm{e}$ também a pesquisa feita pelo IDESP junto ao Congresso Nacional lhe são claramente desfavoráveis. Apesar disso, existe hoje no País um consenso crescente de que o modelo de desenvolvimento articulado nos anos $\mathbf{3 0}$ precisa ser urgentemente revisto. Esse modelo, como dissemos, conferia ao Estado um importante papel empresarial; em algumas formulaçóes, um papel decisivo e praticamente ilimitado, pressupondo-se ao mesmo tempo que a distribuição da renda e a melhoria das condiçóos sociais tenderiam a ocorrer naturalmente, como subproduto do crescimento econômico (vale dizer, do adequado desempenho, pelo setor público, do papel a ele atribuído). A consciência de que essas conseqüências sociais desejáveis não ocorreram, mais que isso, que o país estará exposto ao risco de uma situação crônica de convulsão social, se não avançar rápida e substancialmente na redução 
da pobreza e das desigualdades sociais, é, sem dúvida, uma das causas da reformulaçáo que ora se exige. Neste sentido, o esgotamento a que nos referimos terá de corresponder ao início de um novo ciclo, uma reconstruf o do Estado, com três componentes principais: 1) uma nova delimitaçáo dos setores onde a presença empresarial do Estado ainda pode ser considerada legítima e necessária; 2 ) a redefinição das responsabilidades e do modus faciendi do Estado na área social; 3) a reorganizaçáo institucional, vale dizer, o reexame dos mecanismos de representação política, da federação e do sistema de governo.

A pesquisa Elites/89, feita pelo IDESP junto a oito segmentos da elite brasileira, teve como um de seus principais objetivos apreender a referida reavaliaçáo do modelo de desenvolvimento implantado a partir dos anos 30. São relevantes, sob este aspecto, os dados da Tabela 1 , construída com base numa pergunta amplamente retrospectiva sobre os aspectos nos quais a atuação do governo federal teria sido bem ou mal sucedida, desde 1930. Tomando todo o período de 1930 a 1990 , que abrange a emergência, o apogeu e o legado do getulismo, bem como os governos militares (1964-1985) e a Nova Repuiblica (1985-1990), vemos que existe uma avaliaçáo razoavelmente positiva do que se realizou em termos de institution-building político e de crescimento econômico. No item implantaf o de uma estrutura politica viável para o Pais, $38 \%$ mantêm uma opinião positiva para a média do período. A avaliação negativa (somente $19 \%$ de aprovação) recai sobre os governos militares (1964-1985). Mesmo a Nova Repuiblica (1985-1990) do presidente Sarney, vista como um desastre econômico, conta com $53 \%$ de aprovação, certamente em virtude de um reconhecimento generalizado de que graves dificuldades lhe foram legadas pelos governos militares, de que o retorno ao pluralismo democrático se deu sob condiçóes econômicas extremamente adversas, e da própria complexidade da agenda política, visto que esse foi o período da Assembléia Constituinte. São claramente favoráveis as avaliaçóes referentes ao desenvolvimento da empresa privada e ao crescimento econômico no conjunto do período. No tocante às políticas de desenvolvimento educacional e científico $e$ às sociais propriamente ditas (reduçấo das desigualdades sociais e regionais), essas seis décadas de desenvolvimentismo são vistas pela elite brasileira como um verdadeiro desastre. No que se refere às desigualdades regionais, $22 \%$ acham que houve sucesso no decorrer das seis décadas; $9 \%$ dizem o mesmo em relação ao primeiro governo civil (1985-1990). Em relação às desigualdades sociais a avaliação é pior: $14 \%$ vêem sucesso no conjunto do período, e $7 \%$ conseguem dizer o mesmo a respeito da Nova Repriblica. 
Tabela 1

Pesquisa Elites/89(*) AVALIAÇÃO DO DESEMPENHO DO GOVERNO FEDERAL,
$1930-1990$

(Em porcentagens)

\begin{tabular}{lccc}
\hline & & $\begin{array}{c}\text { O governo federal teve algum, } \\
\text { muito ou total sucesso }\end{array}$ \\
& $1930 / 90$ & $1964 / 85$ & $1985 / 90$ \\
Áreas & 38 & 19 & 53 \\
$\begin{array}{l}\text { Implantação de uma estru- } \\
\text { tura política viável para o }\end{array}$ & & 69 & 28 \\
$\begin{array}{l}\text { País } \\
\text { Estímulo ao desenvolvi- } \\
\text { mento da empresa privada }\end{array}$ & 80 & 41 & 21 \\
$\begin{array}{l}\text { nacional } \\
\text { Prestígio internacional do }\end{array}$ & 49 & 90 & 11 \\
$\begin{array}{l}\text { País } \\
\text { Promoção do crescimento } \\
\text { econômico }\end{array}$ & 90 & 36 & 11 \\
$\begin{array}{l}\text { Promoção do desenvolvi- } \\
\text { mento educacional e cientí- } \\
\text { fico }\end{array}$ & 34 & 22 & 9 \\
$\begin{array}{l}\text { Redução das desigualdades } \\
\text { regionais }\end{array}$ & 22 & 16 & 7 \\
$\begin{array}{l}\text { Reduçáo das desigualdades } \\
\text { sociais }\end{array}$ & 14 & & \\
\hline
\end{tabular}

$\left(^{*}\right)$ Ver explicaçāo sobre a pesquisa na Nota 3. Foram entrevistadas 450 pessoas em 8 setores da elite brasileira. $O$ complemento das porcentagens na tabela corresponde à soma das respostas negativas (pouco ou nenbum sucesso).

A Tabela 2 mede o grau de aceitação a uma afirmação extremadamente liberal - a conveniência de se restringir a atuação do Estado a áreas clássicas, como segurança, educação e justiça. A coluna da esquerda mostra a distribuiçáo das respostas na pesquisa Elites/89; a da direita, na pesquisa Congresso/91. Observa-se que a referida afirmaçáo foi totalmente apoiada por $37 \%$ dos entrevistados da pesquisa Elites/89 e por $46 \%$ da pesquisa Congresso/91. Os dois percentuais são elevados, considerando-se o caráter taxativamente liberal da proposição, mas é ainda mais elevado entre os congressistas. Esse maior liberalismo dos congres- 
sistas se deve mais provavelmente ao intervalo de tempo entre as duas pesquisas, no qual se registraram acontecimentos de enorme importância, sob o ponto de vista aqui considerado, que à diferente composição dos dois grupos. Tudo indica que os congressistas avançaram no sentido da reforma do Estado e da privatização de empresas estatais sob o impacto de um fator externo - o colapso definitivo dos regimes de economia planificada do Leste Europeu e da ex-URSS, e de um fator interno: o megachoque econômico aplicado em março de 1990 pelo recém-empossado governo Collor, cujo fracasso agravou a situação econômica e social do País e evidenciou mais uma vez que o controle de uma superinflaçáo como a brasileira exigirá reformas estruturais profundas.

\section{Tabela 2}

\section{ATUAÇÃO DO ESTADO DEVERIA RESTRINGIR-SE A ÁREAS CLÁSSICAS, COMO EDUCAÇÄO, JUSTIÇA E SEGURANÇA (*) (Porcentagens)}

\begin{tabular}{lll}
\hline & Elites/89 & Congresso/91 \\
\cline { 2 - 3 } Forte concordância & 37 & 46 \\
Concorda em termos & 26 & 23 \\
Forte discordância & 36 & 30 \\
Sem opinião & 1 & 1 \\
\hline$(\mathrm{N}=100)$ & $(450)$ & $(406)$ \\
\hline
\end{tabular}

$\left.{ }^{*}\right)$ Ver explicaçăo sobre as pesquisas na Nota 3.

A Tabela 3 explora o tema da reforma do Estado em funçáo de setores específicos. Observe-se que mesmo o supertabu dos tempos getulistas - o monopólio estatal do petróleo - está sendo revisto. Na pesquisa Elites $/ 89,59 \%$ consideravam indispensável a presença empresarial do Estado nessa área; na pesquisa Congresso/9l esse percentual é de apenas $44 \%$. Văo no mesmo sentido as diferenças registradas no tocante à energia elétrica, às telecomunicaçóes, às ferrovias, à indústria farmacêutica e à siderurgia. A importância destes resultados, como foi sugerido, é que indicam a disposição das elites e do Congresso a aceitar 
SETORES ONDE A ATUAÇÃO EMPRESARIAL DO ESTADO É CONSIDERADA MUITO OU TOTALMENTE NECESSÁRIA (*)

(Porcentagens)

SETORES $\quad$ ELITES/89 CONGRESSO/91

Petróleo

Energia elétrica

Telecomunicaçóes

Ferrovias

Indústria farmacêutica

Siderurgia

Informática

Aviação comercial
59

55

50

47

29

24

15

7
44

38

34

28

17

15

$-\left(^{* *}\right)$

$-\left(^{* * *}\right)$

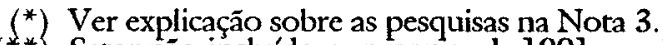

(**) Setor não-incluído na pesquisa de $1991 \mathrm{em}$ virtude da prévia reformulação da legislaçáo, com redução da presença estatal.

$\left(^{* *}\right.$ ) Setor não-incluído em virtude da prévia privatização da VASP, única empresa estatal do setor.

um amplo programa de reforma do Estado, apesar da maciça rejeição ao governo que no momento tenta implementar tais mudanças. Convidados a avaliar o desempenho do governo Collor em seus primeiros dezoito meses, apenas $6 \%$ dos congressistas entrevistados classificaram-no como ótimo ou bom; para $35 \%$ ele seria regular, enquanto uma sólida maioria de $58 \%$ preferiu classificá-lo como ruim ou péssimo (2\% náo quiseram opinar). Mesmo no partido do presidente, o PRN, a avaliaçáo positiva (ótimo ou bom) ficou em $48 \%$; para outros $48 \%$ o governo seria apenas regular ( $4 \%$ classificaram-no como ruim). Parece pois evidente que o Congresso se dispõe a endossar reformas que o Executivo apresenta como bandeiras suas; mas essa disposição nada tinha a ver, no momento da pesquisa, com o desempenho do governo Collor em seus primeiros de- 
zoito meses. Trata-se, antes, de uma importante reorientação no pensamento das elites e dos políticos brasileiros sobre as funções econômicas do setor público; mais que isso, do esgotamento, sem nenhuma dúvida, do modelo que começou a ser implantado há 60 anos, sob a égide do getulismo.

\section{Do tripé dos anos 30 à presente crise institucional}

Náo é menos pronunciado, do ponto de vista político-institucional, o esgotamento do modelo dos anos 30 . O Congresso Constituinte de 1987-88 debateu longamente este problema, mas não conseguiu fixar em definitivo o perfil institucional do País. Meu argumento quanto a estes pontos é que o modelo erigido a partir de 1930 assumiu a forma de um tripé, cada uma das três pontas correspondendo à solução dada a dilemas que haviam emergido em três subsistemas institucionais. A primeira dessas soluções dizia respeito ao formato do subsistema de representação de interesses: a opçáo pelo corporativismo, com a conseqüente rejeiçăo do pluralismo sindical (4). A segunda referia-se ao subsistema representativo no sentido estrito, ou seja, federativo, eleitoral e parlamentar. Nesta área prevaleceu o lado liberal-democrático da elite, aparentemente minoritário na Revolução de 1930. A solução escolhida foi de caráter consociativo, isto é, um arranjo orientado para a proteçáo das minorias políticas contra a formaçáo de maiorias compactas e/ou o exercício desabrido do poder por estas. Finalmente, na terceira ponta, o presidencialismo, ou mais exatamente, a radicalizaçáo plebiscitária da idéia presidencialista. Concentrando o poder no Executivo e canalizando para ele um simbolismo de intensa legitimidade popular, criou-se assim, progressivamente, com o getulismo, um modelo institucional que nada tem a ver com o modelo originariamente escolhido no início da República, de inspiraçáo norte-americana (5).

Com o avanço da complexidade e dos conflitos distributivos próprios a uma sociedade medianamente industrializada, as dificuldades latentes em cada uma dessas três pontas, e na combinação das três, viriam inexoravelmente à tona. Vejamos, em primeiro lugar, o corporativismo. Pretendia-se, com essa opção, remover os conflitos capital/trabalho da arena político-partidária e confiná-los a um subsistema específico, no qual preponderassem enfoques judiciários e administrativos. Na origem, o discurso ideológico pertinente a essa primeira perna do tripé achava-se influenciado, como é fácil imaginar, pelo que genericamente se tem designado como "protofascismo", abrangendo diversas formulaçóes doutrinárias então em voga na direita européia (6).

Longe de assegurar a paz social - vale dizer, o controle perma- 
nente e a regulação meramente administrativa dos conflitos de interesse -, o corporativismo, num estágio avançado de industrialização, tende a dificultar as composiçóes. Isto ocorre, de um lado, pelo falseamento do processo de constituição de interlocutores. Tendo cada sindicato o monopólio da representação numa determinada jurisdição territorial e sendo-lhe atribuída uma participação na receita tributária (o chamado "imposto sindical" ), a mobilização e a busca de vínculos estreitos com a base passa a não interessar racionalmente às lideranças sindicais, salvo conjunturalmente, segundo a evolução específica de algum conflito. Por outro lado, o corporativismo tende a indexar horizontal e verticalmente as reivindicaçốes. No sentido horizontal, porque empresas mais débeis são forçadas a assimilar custos decorrentes da aceitação de reivindicações sindicais por parte de empresas mais fortes que pertencem à mesma categoria. No sentido vertical, porque a obtenção de determinada vantagem por uma categoria sindical é tomada como ponto de referência por outra, que passa imediatamente a reivindicar um múltiplo. Também aqui, as dificuldades apontadas por Olson na mobilizaçáo da açáo coletiva deixam de existir: de um lado, os custos da participação não são sentidos individual e diferenciadamente pelos integrantes da categoria; de outro, os benefícios potenciais transformam-se em bens puiblicos irrealisticamente abrangentes. Em todos estes sentidos, a ação coletiva burocraticamente estruturada pelo sistema corporativista provavelmente dificulta em vez de facilitar a negociação dos conflitos entre capital e trabalho (7). Denunciado há várias décadas como " herança fascista" por sindicalistas e intelectuais de esquerda, o corporativismo permaneceu na Constituiçáo de 1988, com apoio dos sindicatos. Mas é agora corporativismo com uma perna quebrada: o Ministério do Trabalho já não dispóe de instrumentos legais para intervir em sindicatos, como contrapartida ao monopólio legalmente assegurado a um único sindicato para representar uma categoria profissional numa dada base territorial. Em outras palavras, extinguiu-se o controle governamental, mas não se ampliou o controle pelo próprio mercado político, por meio do pluralismo sindical. $O$ desequilíbrio potencial dessa situaçáo é ainda maior se se considera que a Constituição estendeu o direito de sindicalização e de greve aos funcionários públicos $\mathrm{e}$ admitiu a greve nos chamados " setores essenciais", onde era tradicionalmente proibida. Observe-se entretanto que esta fórmula híbrida, a meio caminho entre o corporativismo e o pluralismo, correspondia ao modelo aparentemente desejado pela opiniáo pública, a julgar por pesquisas feitas na época. Como relata Amaury de Souza, "o sentimento dominante da opiniấo pública era a favor da autonomia sindical, entendida como a eliminaçáo dos laços de subordinação dos sindicatos ao governo, e não tanto de adesão ao princípio da 
liberdade de associação" (i.e. ao pluralismo)(8).

Armados com esses novos graus de liberdade que lhes foram concedidos pela Constituição de 1988, os sindicatos tentaram acirrar o conflito trabalhista, convocando duas greves gerais malsucedidas e fazendo numerosas greves em setores antes "essenciais". A consequiência foi uma pronunciada perda de apoio na opinião pública. Constata-se, portanto, que o sistema híbrido previsto na Constituição ainda não encontrou, e talvez não encontre tão cedo, um ponto natural de equilíbrio. Liberado dos antigos controles administrativos, o sindicato encontra pela frente apenas a resistência da Justiça do Trabalho, que pode mandar suspender determinada greve, declarando-a "abusiva", e a força ex post factum da opinião pública. Neste sentido, parece acertada a previsão de Amaury de Souza: "A revisão do processo de greve e da negociação coletiva - com limites ao julgamento e à arbitragem de conflitos de interesse pelo poder judiciário e efetiva proteção aos interesses do público contra as paralisaçóes de serviços ou atividades essenciais - será certamente uma demanda crescente nos próximos anos (ibidem).

A segunda perna do tripé compreende os procedimentos referentes à disputa eleitoral e partidária, à atividade parlamentar e ao relacionamento entre os três níveis da federação. $\mathrm{O}$ dilema básico dos anos 30 , nesta área, era como desmontar o monopólio político antes existente no âmbito de cada estado, formalizado nos partidos republicanos (PRs), que eram, na realidade, partidos únicos estaduais. Ou seja, a questão era como quebrar esse monopólio, abrindo-se a possibilidade da competição eleitoral pacífica, sem entretanto dilatar de maneira drástica ou precipitada o escopo da competiçáo, que era determinado pela própria exigüidade da elite política da época. Para institucionalizar nesse âmbito um certo grau de pluralismo, fazia-se mister implantar regras de jogo embrionariamente consociativas e impedir que violências ou fraudes em larga escala as anulassem na prática. Os modestíssimos índices de participação eleitoral não eram vistos como um problema da mesma gravidade - pelo menos náo no curto prazo (9).

Especificar em que aspectos e em que grau o sistema político brasileiro se assemelha às chamadas democracias consociativas européias tornaria demasiado extenso o presente artigo. Lembrarei apenas que o mecanismo consociativo não significa, no caso brasileiro, concessão de garantias ou equivalências em direitos a minorias étnicas, lingüísticas ou religiosas, dada a pouca projeção de clivagens desse tipo na arena política. Significa, isto $\operatorname{sim}$, a preferência por mecanismos legais acentuadamente fragmentadores, em diferentes níveis do sistema político. O resultado agregado de tais mecanismos é um sistema muito mais voltado 
para um bloqueio multilateral à concentraçăo do poder que para a formação de uma maioria estável, com poder e legitimidade para executar um programa de governo. Os governos militares pós-64 empenharamse, como é sabido, em neutralizar a força fragmentadora desses mecanismos, notadamente pela imposição de um sistema bipartidário e pela redução da autonomia política e financeira dos estados e municípios. Os equívocos e a intrínseca ilegitimidade dessa tentativa condenaram-na, porém, ao fracasso.

A construção de um arcabouço institucional de vocaçáo consociativa teve início logo após a Revolução de 1930 e foi produto de uma política deliberada. Destacavam-se, entre os motivos para essa orientaçăo, a crítica generalizada às práticas políticas da Primeira República, com a virtual impossibilidade do exercício da oposiçáo contra a oligarquia dirigente em cada estado e, especificamente, a ocorrência de duas guerras civis no estado do Rio Grande do Sul. Assim, o Código Eleitoral de 1932 introduziu parcialmente a representação proporcional no País (associado ao voto secreto, à criaçáo de um ramo do Judiciário encarregado de organizar e gerir todo o processo eleitoral, do alistamento à diplomaçáo dos eleitos, e ao voto feminino). Logo após a Segunda Guerra Mundial, a representação proporcional foi aperfeiçoada com a introduçáo do sistema D'Höndt (permanecendo, porém, até hoje as distorçóes decorrentes da adoção dos estados como distritos eleitorais). $\mathrm{Na}$ mesma época, foi recusado o voto em lista bloqueada, em favor do voto preferencial (o eleitor escolhe livremente um candidato individual na lista de um partido). No tocante ao esquema federativo, existe hoje uma controvérsia acentuada a respeito da super-representaçáo dos estados menos populosos na Câmara Federal. Vale a pena frisar, entretanto, que esse dispositivo se consolidou juridicamente após a Revolução de 1930, como reação à situação anterior, na qual dois estados, Săo Paulo e Minas Gerais, praticamente comandavam toda a Federaçáo. Trata-se, portanto, de um reforço ao elemento de consociativismo já inerente ao conceito de federação. Acrescente-se ainda a esta lista de elementos consociativos a existência, desde 1945, de um sistema multipartidário, com extrema facilidade para a formaçáo de partidos e a concessáo quase automática a estes, após o registro legal, de importantes recursos de poder, como o acesso, uma vez por ano, a uma cadeia nacional de rádio e televisão. No bojo da recente redemocratizaçáo, foi finalmente repelido o último entrave ao pleno consociativismo, que era a proscrição dos partidos considerados extremistas (na prática, os marxistas).

Essa característica consociativa do sistema político brasileiro, e principalmente o seu surgimento numa época ainda marcadamente oli- 
gárquica, só agora começa a ser percebida e ressaltada pelos analistas. Dentro do enfoque economicista então predominante, o que se percebia, na melhor das hipóteses, era um discurso de conciliaçăo, sempre entendido como um traço cultural arcaico, sintoma de que a elite dirigente ainda não se livrara completamente de suas raízes oligárquicas e rurais. A idéia de que tais mecanismos estivessem sendo introduzidos como uma fórmula moderna, e que eles talvez tenham sido táo ou mais importantes para a estabilidade política que a retórica protofascista do " Estado forte" - esta idéia só raramente foi considerada. Ao mainstream da historiografia, brasileira e estrangeira, parece até hoje inconcebível que mecanismos dessa natureza possam existir num país latino-americano (ergo de cultura política autoritária?), que passou por dois regimes ditatoriais (1937-1945 e 1964-1985) no período que estamos considerando, e no qual clivagens étnicas, lingüísticas ou religiosas como as que deram origem às democracias consociativas européias de fato náo se projetam com força na arena política (10).

O fato, entretanto, é que há seis décadas o subsistema político-representativo (no sentido já antes definido) vem evoluindo em sentido consociativo. Articulada embrionariamente nos anos 30 , essa orientaçáo ressurgiu a partir de 1945, após a queda da ditadura getulista, e foi levada às últimas conseqüências pelas reformas legais dos anos 80 e pela Constituição de 1988, que consolidaram o retorno ao regime democrático. A conseqüência disso é que o processo partidário e parlamentar brasileiro caracteriza-se por aguda fragmentaçăo, numa medida que náo se pode razoavelmente explicar a partir da diversidade social objetiva e em flagrante contraste com o que se observa na Argentina ou na Venezuela, para não falar no México. Sem entrar nos méritos ou deméritos da presidência Fernando Collor de Mello, ninguém desconhece que a situaçáo de precária governabilidade em que hoje se encontra o País se deve em grande parte à ascensão ao Executivo Federal de um político rigorosamente destituído de base parlamentar. Por mais que se busquem explicaçóes sociológicas de caráter geral para esse fenômeno, seja na rejeiçáo aos velhos políticos, seja numa suposta inclinaçáo populista da cultura política brasileira, existe um fator antecedente e decisivo: o caráter extremamente permissivo da legislaçáo sobre a formação de partidos e sobre $o$ acesso dos mesmos aos meios de comunicação. Sendo ou náo positivos os efeitos da representaçáo proporcional na composiçáo das casas legislativas, a eleiçáo de Collor mostra o forte impacto fragmentador que esse sistema pode produzir sobre o Executivo, ao facilitar a ascensão ao poder de um líder que literalmente não dispunha de quadros para organizar o ministério e preencher os altos cargos da administração federal. 
A terceira perna do tripé é o que em diversos trabalhos tenho chamado de presidencialismo plebiscitário. Se não surgiu durante a Primeira República uma superpresidência, e nem mesmo uma mística superpresidencial, isto se deveu muito mais ao pluralismo oligárquico entáo existente que propriamente à letra da Constituiçáo. O presidente da República, naquele período, era pouco mais que um delegado das principais oligarquias regionais, escolhido por elas e a elas obediente. Com a Revoluçáo de 1930 e principalmente após a repressáo aos extremismos comunista e integralista e a implantaçáo do Estado Novo (1937-1945), começa a surgir a figura do líder apoiado diretamente no povo, transformando-se correlativamente o próprio entendimento do presidencialismo como forma institucional. Tinha início aí a radicalização plebiscitária desse sistema, que o transforma praticamente no oposto do modelo norte-americano dos checks and balances. Se neste último prevalece uma idéia de equilíbrio entre forças equivalentes, no presidencialismo plebiscitário brasileiro (e latino-americano) prevalece a idéia de um Executivo personalizado, como centro de fixação de todo o sistema político; centro único, mais poderoso e que se arroga maior legitimidade que os outros dois poderes, teoricamente iguais e independentes, previstos na Constituição.

Numa sociedade altamente urbanizada e constantemente assolada por superinflações, a suposição de que os presidentes da República poderáo beneficiar-se de um apoio plebiscitário intenso e estável não passa de fantasia. Por natureza efêmero, esse tipo de capital político, ao dissolver-se, deixa um rastro de ressentimentos proporcional às expectativas carismáticas engendradas pelas campanhas eleitorais ou por choques econômicos miraculosos. $\mathrm{Na}$ área das relaçóes capital/trabalho, o acirramento dos conflitos pode ser reduzido por uma recessão violenta como a atual, mas persiste o fato de que o formato mediante o qual se dá a representação dos interesses desfavorece a negociação. Como estamos aqui refletindo sobre o problema institucional em conexáo com a governabilidade, é necessário frisar que os instrumentos à disposição do Executivo são hoje muito limitados. Pela Constituição de 1988, o Executivo já não possui os instrumentos autoritários que, sob roupagens jurídicas diversas, vinham sendo renovados desde os tempos getulistas, notadamente o poder de intervir nos sindicatos e de definir os setores "essenciais" onde a greve não seria permitida.

O repouso normal para as turbulências infelizmente prováveis no quadro que acabamos de esboçar deveria ser o apoio partidário e parlamentar; mas esta saída é também problemática no sistema político brasileiro, que combina o presidencialismo plebiscitário com um subsis- 
tema representativo exacerbadamente consociativo. Reestruturar as relaçóes entre estes três setores é pois o desafio da reforma institucional dos próximos anos. $\mathrm{Na}$ área sindical, como vimos, o que vem ocorrendo é uma flexibilização do corporativismo, não uma transiçăo completa a um sistema pluralista. $\mathrm{Na}$ área político-institucional, caberá aos cidadãos a escolha entre presidencialismo e parlamentarismo. Qualquer que seja a opção, começa a ganhar força no País a convicção de que nenhum dos dois sistemas poderá assegurar a governabilidade em combinação com $o$ pluralismo consociativo nos moldes hoje vigentes. O problema, portanto, é como estruturar politicamente a pluralidade, objetivo que em si mesmo é desejável, mas assegurando ao mesmo tempo, ao poder executivo central, a necessária sustentação.

\section{Parlamentarismo, partidos e sistema eleitoral}

De fato, num sistema formado por partidos mais fortes e em menor número, virtualmente qualquer modelo de parlamentarismo tem melhores chances de produzir maiorias estáveis do que o presidencialismo, seja porque a maioria parlamentar em geral não terá interesse em derrubar o governo que ela mesma constituiu, seja porque, ao fazê-lo, poderá sofrer perdas eleitorais a curto prazo, como decorrência da dissolução da legislatura e da convocação de novas eleiçóes. No caso brasileiro, que é de acentuada fragmentação, penso que esse antídoto inerente ao mecanismo parlamentarista deveria ser reforçado pela inclusão no texto constitucional da chamada mof o de censura construtiva; isto é, a cláusula segundo a qual o Legislativo, para retirar sua confiança no primeiro-ministro, deve designar outro, também por maioria absoluta, no mesmo ato (artigo 67 da Constituição alemã de 1949 e 113 da espanhola de 1978) (11). Incorporada essa cláusula ao modelo parlamentarista que será submetido ao plebiscito de 1993, estaria a meu ver afastado o fantasma da instabilidade assembleista. Afastado, observe-se, sem levar-nos ao outro extremo: a petrificação excessiva a que a moçáo construtiva pode levar um sistema de partidos mais concentrado e disciplinado (como parece ocorrer na Alemanha). Sem querer anunciar a próxima transformaçáo do vício em virtude, penso que essa cláusula neutralizaria em grande parte o risco que a fragmentação partidária brasileira representa para o parlamentarismo; e talvez até a fizesse trabalhar em sentido positivo, evitando a petrificação de uma estabilidade governista tão inaceitável quanto o seu oposto.

Das quatro combinaçóes possíveis entre presidencialismo versus parlamentarismo e representação proporcional : versus majoritária, a "menos atraente", como diz Lijphart, é com certeza presidencialis- 
mo/representação proporcional (12). Facilitando a proliferaçáo partidária, a RP "aumenta a probabilidade de presidentes sem maioria parlamentar e conseqüentemente de impasses entre o Executivo e o Legislativo" . Sabemos, por outro lado, que uma inversão completa da estrutura existente, como a que foi tentada pelo regime militar com a implantação do bipartidarismo, não é um projeto de fácil execução. Tentar reforçá-lo com um sistema distrital puro (majoritário/uninominal) equivale a apresentar duas propostas de difícil trânsito político, em lugar de uma. Constata-se, assim, que a reorganização do presidencialismo envolve dificuldades iguais e eventualmente maiores que o trânsito ao parlamentarismo. Para associá-lo a um modelo majoritário, seria primeiro necessário superar resistências políticas consideráveis; em seguida, certificar-se de que esse modelo náo polarize em excesso as clivagens sociais; e em terceiro lugar, encontrar antídotos institucionais seguros para o potencial autoritário existente nessa combinaçáo do presidencialismo com um modelo globalmente majoritário.

Caso estas considerações estejam corretas, devemos concluir que o caminho mais promissor para a reorganizaçáo institucional do País se encontra na combinação entre parlamentarismo e representação proporcional. Mas parlamentarismo, como disse, munido de defesas (como a mof o de censura construtiva ) contra o fato historicamente consumado da nossa fragilidade partidária; representaçáo proporcional, mas num formato operacional distinto do que temos praticado. Parece-me, sob este último aspecto, que a adaptaçăo do modelo alemáo seria a alternativa apropriada, na medida em que associa o critério proporcional na alocação global das cadeiras a uma mecânica distrital (majoritária) para o preenchimento de metade das vagas, com a prévia exclusáo de partidos que não atinjam $5 \%$ da votaçăo nacional.

\section{Conclusão}

Conquanto o objetivo principal deste artigo tenha sido um mapeamento da evoluçáo institucional brasileira desde os anos 30, há nele também uma avaliação quanto ao futuro da governabilidade democrática no Brasil. Essa avaliaçáo é francamente desfavorável à presente combinação de presidencialismo e sistema eleitoral proporcional (ou, mais amplamente, do presidencialismo com o chamado modelo consociativo da democracia). $\mathrm{Na}$ atual contagem regressiva para o plebiscito de 1993 , devemos considerar seriamente a combinaçáo alternativa do parlamentarismo com o princípio proporcional. No que se refere, porém, ao sistema eleitoral apropriado ao parlamentarismo, o debate apenas se inicia. Além de corresponder ao seu requisito precípuo, como foco da legiti- 
midade democrática, será necessário desenhar um sistema que corresponda da melhor forma possível a estes três critérios específicos: 1) atuar positivamente no sentido da sedimentação e coesão dos partidos; 2) assegurar rapidez e inteligibilidade à nova consulta eleitoral, no evento de dissolução da Câmara; 3) minimizar os custos políticos (e de informação para o eleitor) que decorreráo da própria mudança.

\section{Notas}

1 Thorstein Veblen, Imperial Germany and the Industrial Revolution (Ann Arbor, Michigan: The University of Michigan Press, 1966; ediçāo original da MacMillan, 1915); Mancur Olson Jr., The Rise and Decline of Nations: Economic Growth, Stagflation and Social Rigiditics (New Haven: Yale University Press, 1982).

Existe uma vasta literatura sobre a Revolução de 1930 e seu impacto político e econômico na vida brasileira. Especialmente úteis, tendo em vista o enfoque deste artigo, săo: Boris Fausto, organizador, O Brasil Republicano, v. III (São Paulo: Difel, 1981) e Paulo Brandi, Getílio: da vida para a historia (Rio de Janeiro: Zahar Editores, 1985 ). A influência do legndo getulista no debate constitucional dos anos $\mathbf{8 0}$ é discutida por Amaury de Souza e Bolívar Lamounier no ensaio "A feitura da Nova Constituição: um reexame da cultura política brasileira", in Bolívar Lamounier, De Geisel a Collor: 0 balanfo da transifiño (São Paulo: Editora Sumaré, 1990).

2 Sobre democracias consociativas ou de consenso, ver Arend Lijphart, Democracies: Patterns of Majoritarian and Consensus Gopermment in Twenty-One Countries (New Haven: Yale University Press, 1984).

3 O IDESP (Instituto de Estudos Econômicos, Sociais e Políticos de Săo Paulo) vem desenvolvendo um amplo programa de pesquisas sobre problemas institucionais com base em sturveys, tanto de massa quanto de elite. Os dados utilizados neste artigo provêm de uma pesquisa feita entre novembro de 1989 e junho de 1990 (citada como Elites/90) e outra junto ao Congresso Nacional entre setembro e novembro de 1991 (Congresso/91). Na pesquisa Elites/89, foram entrevistadas 450 pessoas em 8 segmentos da elite: políticos, empresários, líderes sindicais, altos administradores do setor público, intelectuais, jornalistas e empresários de comunicação, líderes associativos e militares (oficiais superiores da Marinha e da Aeronáutica). $\mathrm{Na}$ Congresso/91, foram entrevistados 406 dos 584 parlamentares (71\% dos deputados federais e $60 \%$ dos senadores). Ambas as pesquisas foram realizadas graças ao apoio financeiro da Fundação Ford ao IDESP.

4 Sobre corporativismo e sindicalismo no Brasil, ver especialmente Phillipe Schmitter, Interest Conflict and Political Change in Brazil (Stanford, California: Stanford University Press, 1971); Leôncio Martins Rodrigues, Trabalbadores, sindicatos e industrializagtho (Sāo Paulo: Editora Brasiliense, 1974); Amaury de Souza, The Nature of Corporatiste representation: Leaders and Members of Organized Labor in Brazill (Cambridge, Mass: tese de doutoramento junto ao MIT-Massachusets Institute of Technology, 1978); Youssef Cohen, The Mrnipulation of Consent: The State and Working-Class Consciousness in Brazil (Pittsburgh, PA: Pittsburgh University Press, 1989).

5 Sobre o presidencialismo no Brasil, ver meus ensaios "Brasil: rumo ao parlamentarismo?" , in B. Lamounier, organizador, A opfăo parlamentnrista (São Paulo: Editora Sumaré, 1991) e " Parlamentarismo ó presidencialismo atenuado: el debate actual en 
Brasil", in Dieter Nohlen e Mário Fernández, editores, Presidencialismo versus Parlamentarismo (Caracas, Venezuela: Editorial Nueva Sociedad, 1991).

6 Ver A. James Gregor, The Ideology of Fascism (New York: Free Press, 1969).

7 Sobre a dificiil constituição de interlocutores válidos durante o processo de transição, ver Annaury de Souza e Bolívar Lamounier, Governo e sindicatos no Brasil: a perspectiva dos anos 80 , "Revista Dados", v. 24, n², 1981. Em seu trabalho sobre a relação entre formatos de intermediação de interesses e governabilidade, Schmitter parece sugerir a existência de uma " boa" soluçăo - o corporativismo " natural", do tipo europeu e duas " más" (o pluralismo norte-americano e o corporativismo artificial, do qual o sistema brasileiro é um exemplo). Cf. P. Schmitter, "Interest intermediation and regime governability in contemporary Western Europe and North America", in Suzanne Berger, editor, Orgnnizing Interests in Westem Europe (Cambridge, UK: Cambridge University Press, 1981). Sobre os dilemas da açăo coleriva em grandes grupos, ver Mancur Olson, Jr. The Theory of Collective Action (New York: Schocken Books, 1968).

8 Amaury de Souza, "Sindicatos e greves: a visão do público", in Bolívar Lamounier, organizador, Ouvindo o Brasil: uma analise da opiniāa príblica brasileira boje (São Paulo: Editora Sumaré, 1992).

9 Ver Assis Brasil, Do voto e do modo de votar (Rio de Janeiro: Imprensa Nacional, 1931); Victor Nunes Leal, Coronelismo, enxada e voto (São Paulo: Editora Alfa-Ómega, 1976;

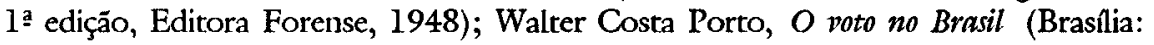
Senado Federal, 1989).

10 Sobre cultura política e democracia no Brasil, ver Bolívar Lamounier e Amaury de Souza, "Changing attitudes towards. Democracy and institutional reform in Brazil", in Larry Diamond, editor, Political Culture and Democracy in Developing Countries (Boulder, Colorado: Lynne Riener Publishers; no prelo); a ser publicado em português pela "Revista Dados".

11 Guilherme D'Oliveira Martins et alli - A Revisão Constitucional e a Mofão de Censura Construtiva (Lisboa: Fundação Friedrich Ebert, 1988).

12 Arend Lijphart, "Forms of Democracy: North-South Comparisons" (Notas preliminares apresentadas à conferência "Norte e Sul na América" ). (Kloster Banz, Alemanha, 6-8 de outubro de 1991.)

\section{Resumo}

A primeira parte do artigo procura demonstrar, com dados de pesquisas feitas pelo Idesp junto às elites brasileiras, que existe um acelerado processo de reorientação ideológica no tocante ao modelo de desenvolvimento econômico iniciado nos anos 30. A segunda argumenta que o modelo político-institucional requer igualmente uma revisão profunda, pois assenta-se sobre um tripé extremamente problemático no que se refere à conformação individual de cada um dos três componentes, e mais ainda quando se pensa na combinação dos três numa mesma estrutura institucional: arranjos exacerbadamente consociarivos na esfera eleitoral-partidária, corporativismo na área sindical e presidencialismo plebiscitáio como suposto fator de unificação, na cumieira do sistema polírico. A terceira delineia a alternativa parlamentarista e o reforço da mesma por meio de mudanças no sistema eleitoral. 


\begin{abstract}
In the first part of the article the author uses surveys conducted by Idesp in order to argue that Brazilian elites are guickly reexamining the ideological conceptions on which the growth model initiated int the 1930's was based. In the second part he argues that the politico-institucional model will also require deep reexamination. According to him that model was an attempt to combine corporatism in the interest representation sphere with strongly consociational electoral and party arrangements and plebiscitarian presidentialism as an would-be unifying factor on top of a highly fragmented system. In the final section the author outlines a parliamentarist alternative and the electoral reforms needed to reinforce it.
\end{abstract}

Bolípar Lamounieré bacharel em Sociologia e Política pela Universidade Federal de Minas Gerais (UFMG) e PH.D em Ciência Política pela Universidade da Califórnia (UCLA). Fundou em 1980 e exerceu durante oito anos a presidência do Instituto de Estudos Econômicos, Sociais e Políticos de São Paulo (Idesp), onde permanece como pequisador senior. Publicou em 1991 A Opção Parlamentarista (Editora Sumaré) e Depois da Transiçáo: Democracia e Eleiçóes no Governo Collor (Editora Loyola).

Trabalho elaborado para a seção " Die langfristigen Auswirkungen der Weltwirtschaftscrise auf die heutigen politischen Systeme", coordenada pelo professor Dieter Nohlen, da Universidade de Heidelberg, por ocasiăo da conferência "Nord und Sud in Amerika: Gegensatze, Gemeinsamkeiten und der europaische Hintergrund", realizada sob os auspícios da Fundação Hanns-Seidel em Kloster Banz (Staffelstein), Alemanha, em outubro de 1991. 